\title{
Differentiation of Xanthomonas spp. Causing Bacterial Spot in Bulgaria Based on Biolog System
}

\author{
Mariya Stoyanova,, Taca Vancheva, ${ }^{2}$ Penka Moncheva, ${ }^{2}$ and Nevena Bogatzevska ${ }^{1}$ \\ ${ }^{1}$ Department of Phytopathology, Institute of Soil Science, Agrotechnologies and Plant Protection "Nikola Poushkarov", \\ 7 Shosse Bankya Street, 1080 Sofia, Bulgaria \\ ${ }^{2}$ Department of General and Industrial Microbiology, Sofia University "St. Kliment Ohridski”, 8 Dragan Tsankov Street, \\ 1164 Sofia, Bulgaria
}

Correspondence should be addressed to Mariya Stoyanova; mistoyanova@abv.bg

Received 18 February 2014; Revised 20 July 2014; Accepted 21 July 2014; Published 14 August 2014

Academic Editor: Joseph Falkinham

Copyright (C) 2014 Mariya Stoyanova et al. This is an open access article distributed under the Creative Commons Attribution License, which permits unrestricted use, distribution, and reproduction in any medium, provided the original work is properly cited.

During the last 20 years, the causative agents of bacterial spot of tomato and pepper have been subjected to many studies and reclassifications. According to the current data, the species are four (X. euvesicatoria, X. vesicatoria, X. gardneri, and X. perforans) and cause similar symptoms in plants but possess different phenotypic properties. This work provides the full metabolic characteristics obtained by Biolog system of bacterial spot's xanthomonads based on a large selection of strains from different vegetable-producing regions of Bulgaria with accent on their major differentiating properties which could be used for species differentiation by metabolic profiles. The results are compared to the data available in the literature in order to clarify the strong features of each species and distinguish the variable ones. Simple characteristics like amylase activity and utilization of cis-aconitate cannot serve alone for differentiation.

\section{Introduction}

Bacterial spot of tomato and pepper plants has been observed in areas with high humidity and warm climate. The disease causes significant losses, estimated of about $10-20 \%$ per year and it is one of the economically most important diseases in all continents where Capsicum annuum and Solanum lycopersicum L. are cultivated. During the last 20 years, the causative agents of bacterial spot have been a subject to many studies and reclassifications [1-5]. Until 1990s, it was considered that the group of strains causing bacterial spot belonged to a single species, Xanthomonas campestris pv. vesicatoria [6], although several phenotypically and phylogenetically distinct groups were observed. In the 1990s, Vauterin et al. [3] transferred groups $\mathrm{A}$ and $\mathrm{C}$ into Xanthomonas axonopodis pv. vesicatoria on the basis of DNA homology among a large number of xanthomonads, and group B was separated at species level as Xanthomonas vesicatoria. The group $\mathrm{D}$ which was firstly isolated in former Yugoslavia [7] was given a species status as Xanthomonas gardneri $[4,5]$. A new species was proposed for the weakly amylolytic group A strains, Xanthomonas euvesicatoria. Currently, the pathogen belongs to four widely distributed species: X. euvesicatoria, X. vesicatoria, X. gard$n e r i$, and $X$. perforans $[5,8]$. According to the current data, the four species cause similar symptoms but possess different phenotypic properties. Species-specific primers have been designed for detection of each of the xanthomonads; however, for the purposes of the routine identification, a more common approach is much preferable. Biolog system which is based on ability for utilization of different carbon sources has proved to be very convenient to complete diagnostics. It has been successfully used for different bacteria including xanthomonads. This study aims to provide the full metabolic profiles of the bacterial spot's xanthomonads based on a large selection of strains from Bulgaria with accent on their major differentiating characteristics which could be used for species 
identification by metabolic profiles. The results are compared to the data in the literature in order to clarify the strong features of each species and distinguish the variable ones.

\section{Materials and Methods}

One hundred eighty-four bacterial strains were the object of this study. The strains originate from different pepper and tomato producing regions of Bulgaria. Eighty-three of them were isolated from pepper (1999-2012) and seventy-four from tomato (1985-2012) plants with symptoms of bacterial spot. Twenty-seven strains were derived from the resident phase of the pathogen on weeds (1989-1999) from and around tomato fields. The bacteria were identified by PCR amplification with species-specific primers as Xanthomonas euvesicatoria (54 strains from pepper), Xanthomonas vesicatoria (115 strains: 29 from pepper, 59 from tomato, and 27 from weeds) and Xanthomonas gardneri (15 from tomato) $([9,10]$, Kizheva et al., unpublished). Biolog GN2 (Biolog, Inc., Hayward, CA, USA) microplates were used for obtaining metabolic fingerprints. The bacteria were incubated on BUG agar at $28^{\circ} \mathrm{C}$ for $24 \mathrm{~h}$ prior to analysis. The procedure was held according to the manufacturer's instructions. Control for repeatability was held by second testing of blindly chosen strains. The results were cluster analyzed to differentiate the strains according to their metabolic profiles. The analysis was performed through the SPSS hierarchical cluster analysis procedure by Ward's method. The matrix of similarity between the isolates was calculated using the Squared Euclidean distance [11-14]. Amylase activity was tested on starch agar medium [15]. The type cultures $X$. vesicatoria NBIMCC $2427, X$. euvesicatoria NBIMCC 8731, and X. gardneri NBIMCC 8730 were used.

\section{Results}

The key phenotypic characteristics described by Jones et al. [5], amylase activity and utilization of cis-aconitic acid for differentiation of the Xanthomonas species that cause bacterial spot of tomato and pepper, were determined (Table 1). Although some variation among the species is observed, these properties are not stably positive or negative.

According to the metabolic patterns obtained by BIOLOG microplates, $\alpha$-cyclodextrine, $\mathrm{N}$-acetylgalactosamine, adonitol, inositol, D-glucosaminic acid, sebacic acid, and histidine were not utilized. More than $93 \%$ of all strains did not utilize also i-erythritol, L-rhamnose, D-sorbitol, D-galactonic acid lactone, D-gluconic acid, $\gamma$-hydroxybutyric acid, p-hydroxy phenylacetic acid, $\alpha$ keto-valeric acid, quinic acid, saccharic acid, L-leucine, L-ornithine, L-phenylalanine, L-pyroglutamic acid, Dserine, thymidine, phenylethylamine, and putrescine and utilized $\alpha$-D-glucose, L-fucose, and sucrose. The reaction of the Bulgarian isolates differed to 67 substrates (Table 2).

The Biolog metabolic data distributes the strains into three clusters at $70 \%$ similarity (Figure 1). The major cluster consists of only $X$. vesicatoria strains; the second big cluster is predominantly formed by strains of $X$. euvesicatoria; the smallest cluster comprises several miniclusters each of which is composed by the three Xanthomonas species (Figure 1). The strains separate in different clusters after analysis only on the basis of a selection of substrates which tend to be utilized differently by the three species (Table 3; Figure 2).

\section{Discussion}

Simple characteristics like amylase activity and utilization of cis-aconitic acid showed some variances and according to our data cannot be used solely for species differentiation.

Clusters based on the metabolic fingerprints of the Bulgarian Xanthomonas isolates from tomato, pepper, and weeds reveal that $X$. euvesicatoria, $X$. vesicatoria, and $X$. gardneri distribute comparatively separated according to the species. However, the smallest cluster includes all the three species and some $X$. gardneri isolates are grouped together with most of the $X$. euvesicatoria strains which refers to the insufficient number of strongly differentiating metabolic features among the species. Detailed overview of the data of the utilization patterns (Table 2) shows that none of the substrates included in the Biolog microplates is strongly utilized by one of the species and is indifferent for the others, and vice versa. However, on the basis of a multiple comparison of the nutrition properties, 27 of the substrates (Table 3) can serve for species differentiation of the causal agents of bacterial spot of tomato and pepper. A notable characteristic of X. gardneri is the significantly lower nutritional properties. This species generally utilizes 14 substrates less than $X$. euvesicatoria and $X$. vesicatoria. Since the reaction of $X$. gardneri to these carbon sources is always negative, this species can easily be distinguished from the other two. $X$. euvesicatoria and $X$. vesicatoria seem to be much similar at first sight. They can be differentiated according to mainly 7 substrates toward which the reaction of $X$. euvesicatoria is consistent. $X$. vesicatoria is a much versatile species. Its reaction according to the data for the Bulgarian strains can vary towards almost all of the differentiating substrates, though it separates best in the hierarchical cluster analysis based on the full metabolic patterns (Figure 1).

Cluster analysis based on the selection of 27 substrates (Table 3) divides the strains into three distinct groups corresponding to their species (Figure 2) and illustrates the high probability for species differentiation based on these metabolic properties. Though identification cannot be guaranteed using this pattern, generally the three species could be successfully distinguished on the basis of the selected differentiating substrates.

The metabolic data obtained shows similarities as well as differences compared to the data available in the literature [2$4,16]$.

Light differences in the utilization of six substrates were observed between the Bulgarian isolates of $X$. euvesicatoria and the isolates studied by Jones et al. [4]. N-acetyl-Dglucosamine, D-galactose, maltose, and bromosuccinic acid were not strongly utilized by all Bulgarian strains with 14$19 \%$ of them being weak positive and $3-8 \%$ negative. Lactic acid and $\alpha$-glycerol-phosphate were not strongly negative but were utilized by $2 \%$ of our strains and weakly utilized by $82 \%$ 
TABLE 1: Utilization of cis-aconitic acid and amylase activity by the Bulgarian strains of genus Xanthomonas isolated from pepper, tomato, and weeds.

\begin{tabular}{lcccccc}
\hline \multirow{2}{*}{ Substrates } & \multicolumn{2}{c}{ X. euvesicatoria } & \multicolumn{2}{c}{ X. vesicatoria } & \multicolumn{2}{c}{ X. gardneri } \\
& + (positive), $\%$ & - (negative), $\%$ & + (positive), $\%$ & - (negative), $\%$ & + (positive), $\%$ & $-($ negative), $\%$ \\
\hline Cis-aconitic acid & $91+7^{*}$ & 2 & $20+36^{*}$ & 44 & 0 & 100 \\
Amylase & 56 & 44 & 95 & $5^{* *}$ & 13 & 87 \\
\hline
\end{tabular}

${ }^{*}$ Strains, $\%$ with positive $+\%$ with weak positive reaction.

${ }^{* *}$ The $5 \%$ strains with negative reaction are all pepper isolates.

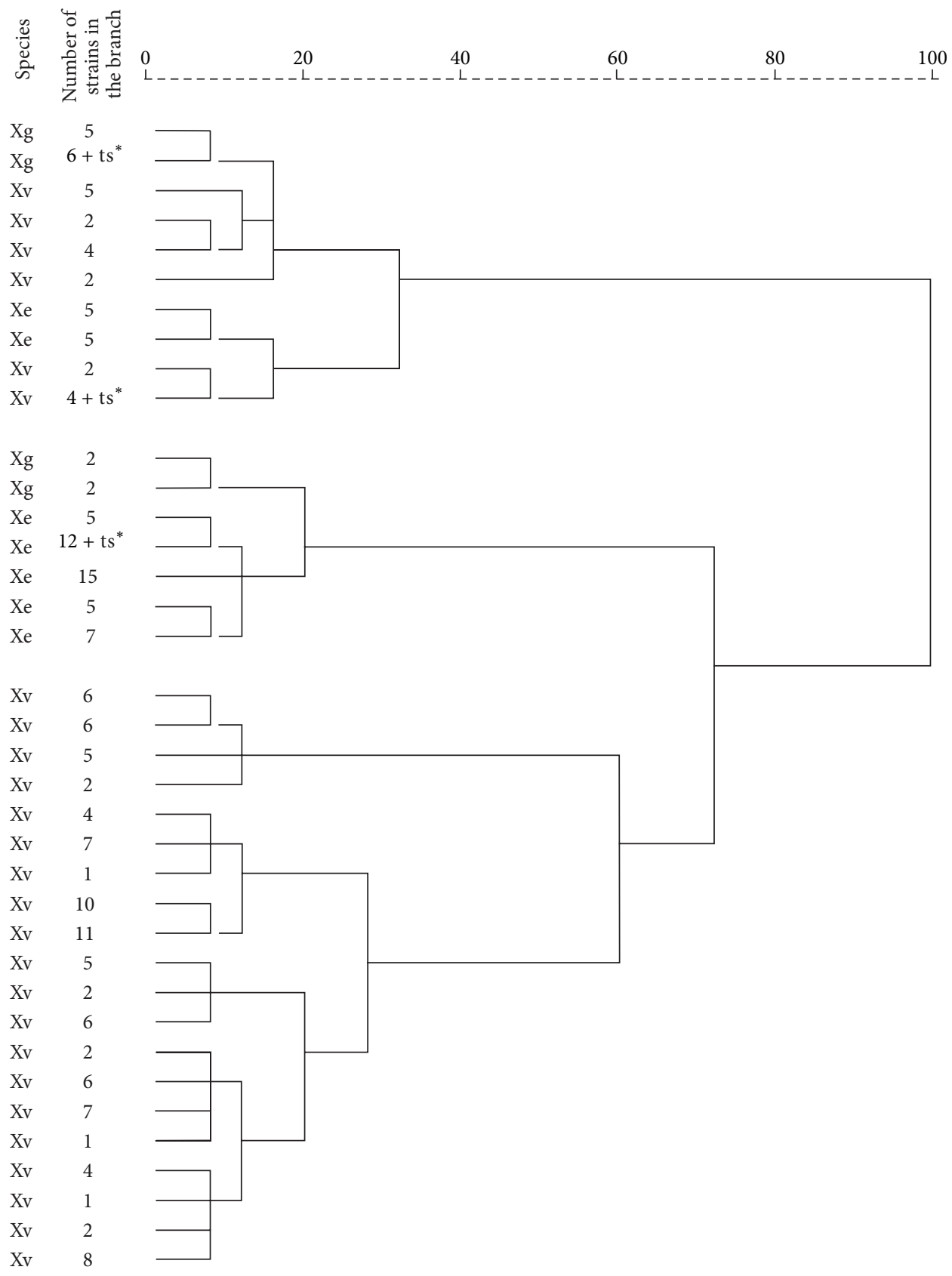

$\begin{array}{ll}\text { Xg: X. gardneri } & \text { Xe: X. euvesicatoria } \\ \text { Xv: X. vesicatoria } & * \text { ts: Type strain for the relevant species }\end{array}$

FIGURE 1: Cluster analysis of the Bulgarian strains of genus Xanthomonas isolated from pepper, tomato, and weeds based on their Biolog metabolic patterns. 
TABLE 2: Differences in utilization of BIOLOG GN2 substrates by the Bulgarian strains of genus Xanthomonas isolated from pepper, tomato, and weeds.

\begin{tabular}{|c|c|c|c|c|c|c|}
\hline \multirow{2}{*}{ Substrates } & \multicolumn{2}{|c|}{ X. euvesicatoria } & \multicolumn{2}{|c|}{ X. vesicatoria } & \multicolumn{2}{|c|}{ X. gardneri } \\
\hline & + (positive), $\%$ & / (weak positive), $\%$ & + (positive), $\%$ & / (weak positive), $\%$ & + (positive), $\%$ & / (weak positive), \% \\
\hline Dextrin & 77 & 23 & 87 & 11 & 7 & 40 \\
\hline Glycogen & $3^{*}$ & 19 & 78 & 16 & 0 & 0 \\
\hline Tween 40 & 100 & 0 & 47 & 47 & $27^{*}$ & 33 \\
\hline Tween 80 & 48 & 52 & 37 & 60 & 20 & 80 \\
\hline $\mathrm{N}$-acetyl-D-glucosamin & 78 & 15 & 70 & 6 & 27 & 13 \\
\hline L-arabinose & 0 & 0 & $14^{*}$ & 2 & 0 & 20 \\
\hline D-arabitol & 0 & 0 & 4 & 13 & 0 & 0 \\
\hline Cellobiose & 100 & 0 & 71 & 20 & 100 & 0 \\
\hline L-Fucose & 92 & 8 & 82 & 14 & $60^{*}$ & 27 \\
\hline D-Galactose & 80 & 15 & 80 & 17 & 40 & 20 \\
\hline Gentibiose & 98 & 0 & 83 & 14 & 0 & 20 \\
\hline$\alpha$-D-lactose & 0 & 0 & 0 & 0 & 40 & 0 \\
\hline Lactulose & 75 & 10 & 79 & 10 & 47 & 13 \\
\hline Maltose & 78 & 14 & 82 & 10 & 0 & 0 \\
\hline D-Mannitol & 0 & 0 & 44 & 18 & 0 & 0 \\
\hline D-Mannose & 93 & 7 & 84 & 13 & 100 & 0 \\
\hline Melibiose & 83 & 15 & 60 & 28 & 60 & 7 \\
\hline$\beta$-methyl D-glucoside & 0 & 5 & 1 & 13 & 0 & 0 \\
\hline D-Psicose & 15 & 53 & 47 & 50 & 87 & 13 \\
\hline D-Raffinose & 17 & 73 & 6 & 26 & 20 & 40 \\
\hline Trehalose & 100 & 0 & 90 & 10 & 80 & 20 \\
\hline Turanose & 0 & 47 & 8 & 38 & 0 & 0 \\
\hline Xylitol & 0 & 0 & 0 & 0 & 7 & 7 \\
\hline Methyl-pyruvate & 92 & 0 & 93 & 6 & $60^{*}$ & 13 \\
\hline Mono-methyl succinate & 89 & 8 & 77 & 20 & 86 & 7 \\
\hline Acetic acid & 9 & 55 & 10 & 26 & $7^{*}$ & 33 \\
\hline cis-Aconitic acid & 91 & 7 & 20 & 36 & 0 & 0 \\
\hline Citric acid & 39 & 24 & 33 & 23 & 20 & 13 \\
\hline Formic acid & 0 & 0 & 3 & 5 & 0 & 0 \\
\hline D-Galacturonic acid & 0 & 0 & 0 & 16 & 0 & 0 \\
\hline D-Glucuronic acid & 0 & 0 & 3 & 11 & 0 & 0 \\
\hline$\alpha$-hydroxybutiric acid & 0 & 30 & 11 & 16 & 0 & 0 \\
\hline$\beta$-hydroxybutiric acid & 0 & 3 & 3 & 10 & 0 & 0 \\
\hline Itaconic acid & 0 & 0 & 3 & 11 & 0 & 0 \\
\hline$\alpha$-kato butyric acid & 5 & 30 & 7 & 19 & 0 & 0 \\
\hline$\alpha$-kato glutaric acid & 95 & 0 & 95 & 3 & 33 & 0 \\
\hline Lactic acid & 2 & 82 & 17 & 50 & 0 & 20 \\
\hline Malonic acid & $28^{*}$ & 55 & 40 & 28 & 0 & 0 \\
\hline Propionic acid & 15 & 31 & 28 & 21 & 0 & 0 \\
\hline Succinic acid & 90 & 3 & 85 & 12 & $33^{*}$ & 0 \\
\hline Bromo-succinic acid & 78 & 19 & 88 & 9 & $33^{*}$ & 0 \\
\hline Succinamic acid & 9 & 60 & 71 & 26 & $33^{*}$ & 0 \\
\hline Glucuronamid & 0 & 0 & 2 & 12 & 0 & 0 \\
\hline Alaninamide & 97 & 0 & 79 & 18 & $7^{*}$ & 27 \\
\hline D-alanine & 79 & 14 & 63 & 20 & $0^{*}$ & 33 \\
\hline L-alanine & 94 & 3 & 78 & 19 & $0^{*}$ & 33 \\
\hline L-alanyl-glycine & 97 & 0 & 66 & 23 & 0 & 80 \\
\hline Asparagine & 0 & 0 & 5 & 17 & 0 & 0 \\
\hline L-aspartic acid & 0 & 53 & 27 & 23 & $7^{*}$ & 7 \\
\hline
\end{tabular}


TABLE 2: Continued.

\begin{tabular}{|c|c|c|c|c|c|c|}
\hline \multirow{2}{*}{ Substrates } & \multicolumn{2}{|c|}{ X. euvesicatoria } & \multicolumn{2}{|c|}{ X. vesicatoria } & \multicolumn{2}{|c|}{ X. gardneri } \\
\hline & + (positive), $\%$ & / (weak positive), \% & + (positive), $\%$ & / (weak positive), \% & + (positive),$\%$ & / (weak positive), \% \\
\hline L-Glutamic acid & 97 & 0 & 83 & 14 & 27 & 0 \\
\hline Glycyl-L-Aspartic acid & 0 & 0 & 5 & 15 & 0 & 0 \\
\hline Glycyl-L-Glutamic acid & 92 & 5 & 41 & 30 & 0 & 20 \\
\hline Hydroxy L-Proline & 41 & 42 & 34 & 31 & $0^{*}$ & 13 \\
\hline L-proline & 3 & 36 & 14 & 21 & 0 & 0 \\
\hline L-Serine & $80^{*}$ & 5 & 24 & 49 & $13^{*}$ & 20 \\
\hline L-Threonine & 0 & 69 & 11 & 26 & 0 & 0 \\
\hline Carnitine & 0 & 7 & 0 & 35 & 0 & 0 \\
\hline$\gamma$-aminobutyric acid & 0 & 3 & 0 & 45 & 0 & 0 \\
\hline Urocanic acid & 0 & 5 & $18^{*}$ & 29 & 0 & 0 \\
\hline Inosine & 0 & 47 & 3 & 18 & 0 & 0 \\
\hline Uridine & 0 & 39 & 3 & 16 & 0 & 0 \\
\hline 2-amino-ethanol & 0 & 0 & 1 & 24 & 0 & 0 \\
\hline Butanediol & 0 & 12 & 0 & 28 & 0 & 0 \\
\hline Glycerol & 74 & 9 & 73 & 22 & 0 & 0 \\
\hline$\alpha$-glycerol-phosphate & 2 & 55 & $50^{*}$ & 42 & 0 & 0 \\
\hline Glucose-1-phosphate & 0 & 28 & $47^{*}$ & 40 & 0 & 0 \\
\hline Glucose-6-phosphate & 0 & 25 & $33^{*}$ & 36 & 0 & 0 \\
\hline
\end{tabular}

${ }^{*}$ Major differences from the strains studied by Jones et al. (2000) [4].

TABLE 3: Differentiating properties for the three Xanthomonas species according to the metabolic patterns of the Bulgarian strains.

\begin{tabular}{|c|c|c|c|}
\hline Substrates & X. euvesicatoria & X. vesicatoria & X. gardneri \\
\hline Glycogen & $v-$ & $v+$ & - \\
\hline Cellobiose & + & $v$ & + \\
\hline Gentibiose & + & $v+$ & $v-$ \\
\hline$\alpha$-D-lactose & - & - & $v$ \\
\hline Maltose & $v+$ & $v$ & + \\
\hline D-Mannitol & - & $v$ & - \\
\hline Turanose & - & $v$ & - \\
\hline cis-Aconitic acid & $v+$ & $v$ & - \\
\hline$\alpha$-hydroxybutiric acid & $v-$ & $v$ & - \\
\hline$\alpha$-keto butyric acid & $v-$ & $v$ & - \\
\hline Propionic acid & $v$ & $v$ & - \\
\hline L-alanine & + & $v$ & $v-$ \\
\hline Asparagine & - & $v-$ & - \\
\hline L-Glutamic acid & + & $v+$ & $v$ \\
\hline Glycyl-L-Aspartic acid & - & $v-$ & - \\
\hline Glycyl-L-Glutamic acid & $v+$ & $v$ & $v-$ \\
\hline L-proline & $v$ & $v$ & - \\
\hline L-Threonine & $v$ & $v$ & - \\
\hline$\gamma$-aminobutyric acid & - & $v$ & - \\
\hline Urocanic acid & - & $v$ & - \\
\hline Inosine & $v$ & $v-$ & - \\
\hline Uridine & $v$ & $v-$ & - \\
\hline Butanediol & $v-$ & $v$ & - \\
\hline Glycerol & $v$ & $v$ & - \\
\hline$\alpha$-glycerol-phosphate & $v$ & $v$ & - \\
\hline glucose-1-phosphate & $v$ & $v$ & - \\
\hline glucose-6-phosphate & $v-$ & $v$ & - \\
\hline
\end{tabular}

+, positive; $v+$, more than $75 \%$ positive; $v$, variable; $v-$, more than $75 \%$ negative; - , negative. 


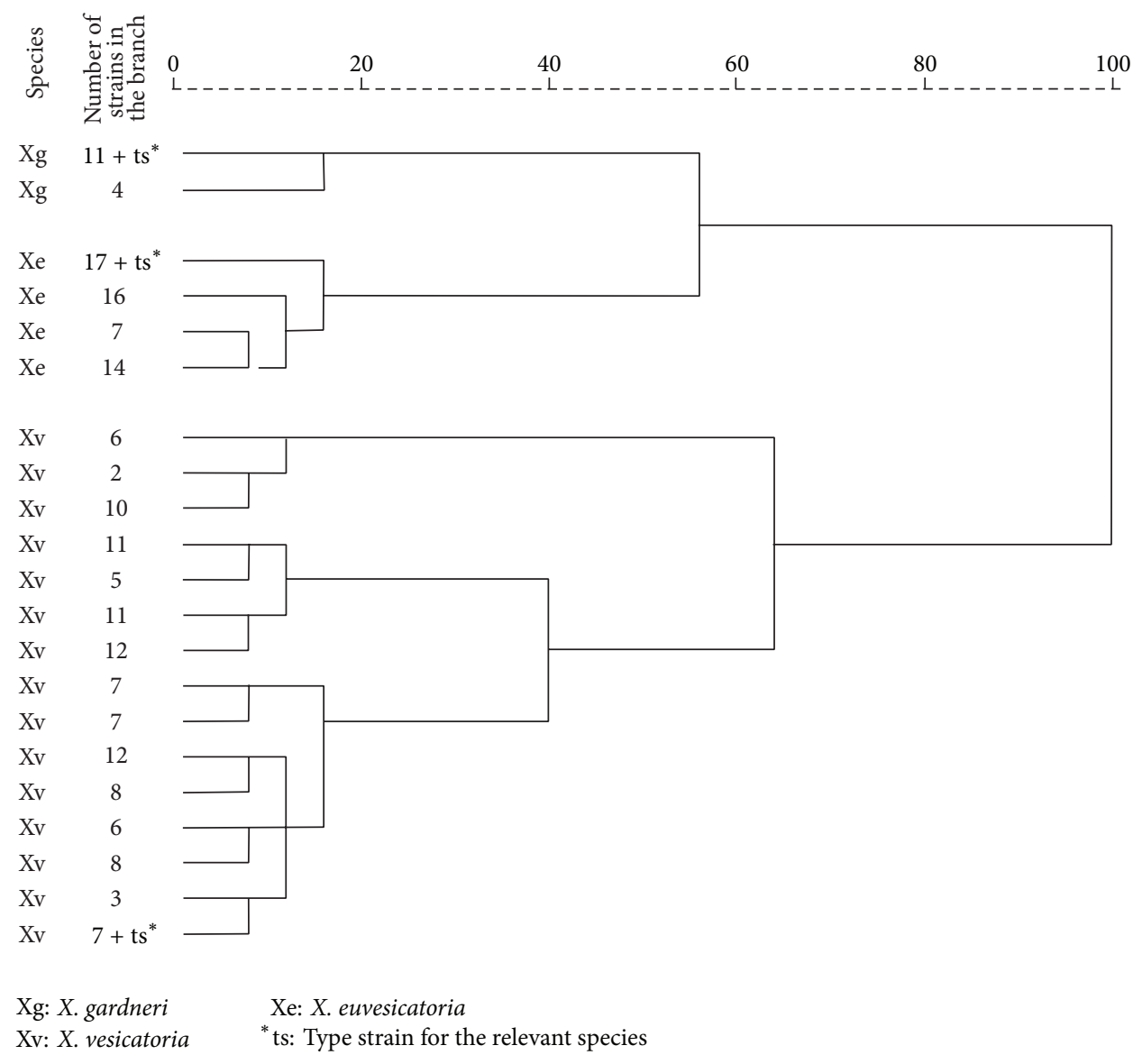

Figure 2: Cluster analysis of the Bulgarian strains of genus Xanthomonas isolated from pepper, tomato, and weeds based on their differentiating properties.

and 55\%, respectively. However, N-acetyl-D-glucosamine, Dgalactose, and L-serine were also not utilized by all strains studied by Vauterin et al. [3] with a difference between the positive strains of Vauterin and ours of less than $10 \%$.

Great differences were observed between the Bulgarian isolates of $X$. euvesicatoria and the isolates studied by Jones et al. [4] in the data for three substrates. Glycogen, malonic acid, and L-serine which were utilized by Jones' strains were negative for $78 \%, 17 \%$, and $15 \%$ of our strains, respectively. While $80 \%$ of the Bulgarian strains still utilized L-serine, the reaction of $55 \%$ of our isolates to malonic acid was only weakly positive. Malonic acid was also among the carbon sources with variable reaction as stated by Vauterin et al. [3] with a difference between the positive strains of Vauterin and ours of $\sim 30 \%$. Other substrates like melibiose and lactic acid were utilized by more Bulgarian strains than those studied by Vauterin et al. [3], and all of our isolates did not show a strong positive reaction to L-aspartic acid, inosine, uridine, glucose-1-phosphate, and glucose-6-phosphate as opposed to Vauterin's ones.

$X$. vesicatoria isolates from Bulgaria manifested light differences in ten substrates as compared to the data available in the literature [2]. Instead of being positive, only $47 \%$,
$77 \%$, and $85 \%$ of the Bulgarian strains were strongly positive to tween 40 , monomethyl succinate, and succinic acid, respectively. Between $3 \%$ and $6 \%$ of the isolates were negative to the same substrates. Between $1 \%$ and $5 \%$ of the strains were strongly positive and $10 \%$ and $18 \%$ of them were only weakly positive to $\beta$-methyl D-glucoside, $\beta$-hydroxybutyric acid, itaconic acid, glucuronamide, asparagine, inosine, and uridine instead of being all negative as stated by [2]. Great differences were observed in the utilization of L-arabinose, urocanic acid, $\alpha$-glycerol-phosphate, glucose-1-phosphate, and glucose-6-phosphate which were positive for $14 \%, 18 \%$, $50 \%, 47 \%$, and $33 \%$ of the strains, respectively, instead of not being preferred as a sole carbon source. A great number of strains (between $29 \%$ and $42 \%$ ) gave also a weak positive reaction to urocanic acid, $\alpha$-glycerol-phosphate, glucose-1phosphate, and glucose-6-phosphate. However, a more recent study of $X$. vesicatoria isolates from Tanzania [16] indicated a positive reaction of these strains to glucose-6-phosphate as opposed to Bouzar et al.s data [2].

Tanzanian isolates manifested some differences in their carbon sources preferences according to the data published before [16]. The Bulgarian isolates differed from these strains in their reaction to 12 substrates. While most of our strains 
(60-78\%) were still positive and $18-28 \%$ were weakly positive to melibiose, monomethyl succinate, D-alanine, L-alanine, L-alanyl-glycine, and glycerol, only some were positive to glycyl-L-glutamic acid (41\% strongly and 30\% weakly), cisaconitic acid (20\% strongly and 36\% weakly), lactic acid (17\% strongly and 50\% weakly), L-proline (14\% strongly and $21 \%$ weakly), L-aspartic acid (27\% strongly and $23 \%$ weakly), hydroxy L-proline (34\% strongly and 31\% weakly), and glucose-6-phosphate (33\% strongly and 36\% weakly), and the reaction to $\beta$-methyl D-glucoside and inosine was predominantly negative and positive with only $1 \%$ and $3 \%$ of the strains, respectively.

Greatest differences existed between the Bulgarian strains of $X$. gardneri and the data in the literature. The Bulgarian strains manifested different preferences from the ones described in the literature to eleven substrates. According to Jones et al. [5], X. gardneri did not use D-alanine, Lalanine, and hydroxy L-proline. Seven percent of our strains utilized acetic acid, alaninamide, and L-aspartic acid; $27-33 \%$ showed a weak positive reaction to acetic acid, alaninamide, D-alanine, and L-alanine; and 7-13\% were weakly positive to L-aspartic acid and hydroxy L-proline. L-fucose was stated to be strongly preferred carbon source [5]; however, $27 \%$ of our strains were only weak positive and $13 \%$ were negative. Methyl-pyruvate and tween 40 were not utilized by $27 \%$ and $40 \%$ of the Bulgarian strains, respectively, and $67 \%$ of the strains were negative to succinic acid, bromosuccinic acid, succinamic acid, and L-serine as opposed to Jones et al. [5].

Instead of negative reaction, a great part of the Bulgarian strains utilized $\alpha$-D-lactose ( $40 \%$ positive), lactulose ( $47 \%$ positive and $13 \%$ weak positive), D-raffinose (20\% positive and $40 \%$ weak positive), citric acid (20\% positive and $13 \%$ weak positive), and L-glutamic acid ( $27 \%$ positive).

The differences manifested by the Bulgarian Xanthomonas strains compared to the data in the literature $[2,3,5]$ can be due to various reasons related to geographical region, climatic conditions, and used cultivars. However, large studies from different regions give the possibility of more accurate evaluation of the strict and the variable bacterial features.

Although $X$. euvesicatoria, $X$. vesicatoria, and $X$. gardneri cannot be distinguished on the basis of simple characteristics like amylase activity and utilization of cis-aconitate or on the basis of individual biochemical tests, the comparison of multiple nutritional properties included in Biolog system can serve for species differentiation of the causal agents of bacterial spot.

\section{Conflict of Interests}

The authors declare that there is no conflict of interests regarding the publication of this paper.

\section{References}

[1] R. E. Stall, C. Beaulieu, D. Egel et al., "Two genetically diverse groups of strains are included in Xanthomonas campestris pv. vesicatoria," International Journal of Systematic Bacteriology, vol. 44, no. 1, pp. 47-53, 1994.
[2] H. Bouzar, J. B. Jones, R. E. Stall et al., "Physiological, chemical, serological, and pathogenic analyses of a worldwide collection of Xanthomonas campestris pv. vesicatoria strains," Phytopathology, vol. 84, no. 7, pp. 663-671, 1994.

[3] L. Vauterin, B. Hoste, K. Kersters, and J. Swings, "Reclassification of Xanthomonas," International Journal of Systematic Bacteriology, vol. 45, no. 3, pp. 472-489, 1995.

[4] J. B. Jones, H. Bouzar, R. E. Stall et al., "Systematic analysis of xanthomonads (Xanthomonas spp.) associated with pepper and tomato lesions," International Journal of Systematic and Evolutionary Microbiology, vol. 50, no. 3, pp. 1211-1219, 2000.

[5] J. B. Jones, G. H. Lacy, H. Bouzar, R. E. Stall, and N. W. Schaad, "Reclassification of the xanthomonads associated with bacterial spot disease of tomato and pepper," Systematic and Applied Microbiology, vol. 27, no. 6, pp. 755-762, 2004.

[6] J. M. Younga, D. W. Dye, J. F. Bradbury, C. G. Panagopoulos, and C. F. Robbs, "A proposed nomenclature and classification for plant pathogenic bacteria," New Zealand Journal of Agricultural Research, vol. 21, no. 1, pp. 153-177, 1939.

[7] D. Sutic, Bakterioze Crvenog Patlidzana (Tomato Bacteriosis), vol. 6 of Posebna Izdanja, Institut za Zaštitu Bilja, Belgrade, Serbia, 1957, English Summary: Review of Applied Mycology, vol. 36, pp. 734-735, 1957.

[8] OEPP/EPPO, "PM 7/110 (1) Xanthomonas spp. (Xanthomonas euvesicatoria, Xanthomonas gardneri, Xanthomonas perforans, Xanthomonas vesicatoria) causing bacterial spot of tomato and sweet pepper," OEPP/EPPO Bulletin, vol. 43, pp. 7-20, 2013.

[9] Y. Kizheva, T. Vancheva, P. Hristova, M. Stoyanova, N. Bogatzevska, and P. Moncheva, "Diversity of Xanthomonas spp. causal agents of bacterial spot on pepper and tomato plants in Bulgaria," Biotechnology and Biotechnological Equipment, vol. 25, no. 5, pp. 1-7, 2011.

[10] Y. Kizheva, T. Vancheva, P. Hristova et al., "Identification of Xanthomonas strains from tomato and pepper and their sensitivity to antibiotics and copper," Bulgarian Journal of Agricultural Science, vol. 19, supplement 2, pp. 80-82, 2013.

[11] J. Ward, "Hierarchical grouping to optimize an objective function," Journal of the American Statistical Association, vol. 58, pp. 236-244, 1963.

[12] L. Kaufman and P. J. Rousseeuw, Finding Groups in Data, John Wiley \& Sons, New York, NY, USA, 1990.

[13] B. S. Everitt, Cluster Analysis, Edward Arnold, London, UK, 3rd edition, 1993.

[14] B. S. Everitt, S. Landau, and M. Leese, Cluster Analysis, Edward Arnold, London, UK, 2001.

[15] N. W. Schaad, "Initial identification of common genera," in Laboratory Guide for Identification of Plant Pathogenic Bacteria, N. Schaad, J. Jones, and W. Chun, Eds., pp. 1-11, APS Press, St. Paul, Minn, USA, 3rd edition, 2001.

[16] K. C. Shenge, R. B. Mabagala, and C. N. Mortensen, "Identification and characterization of strains of Xanthomonas campestris pv. Vesicatoria from Tanzania by biolog system and sensitivity to antibiotics," African Journal of Biotechnology, vol. 6, no. 1, pp. 15-22, 2007. 

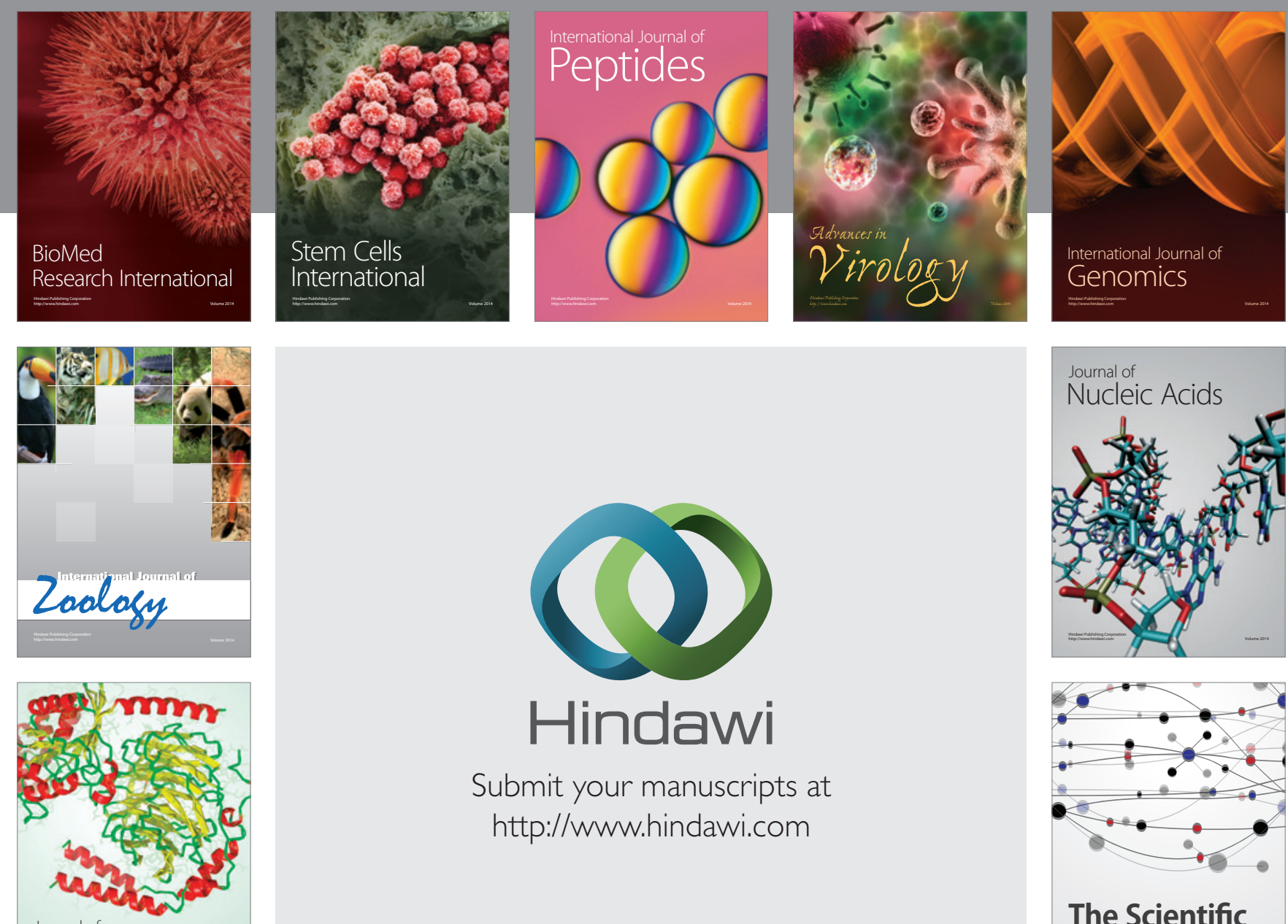

Submit your manuscripts at

http://www.hindawi.com

Journal of
Signal Transduction
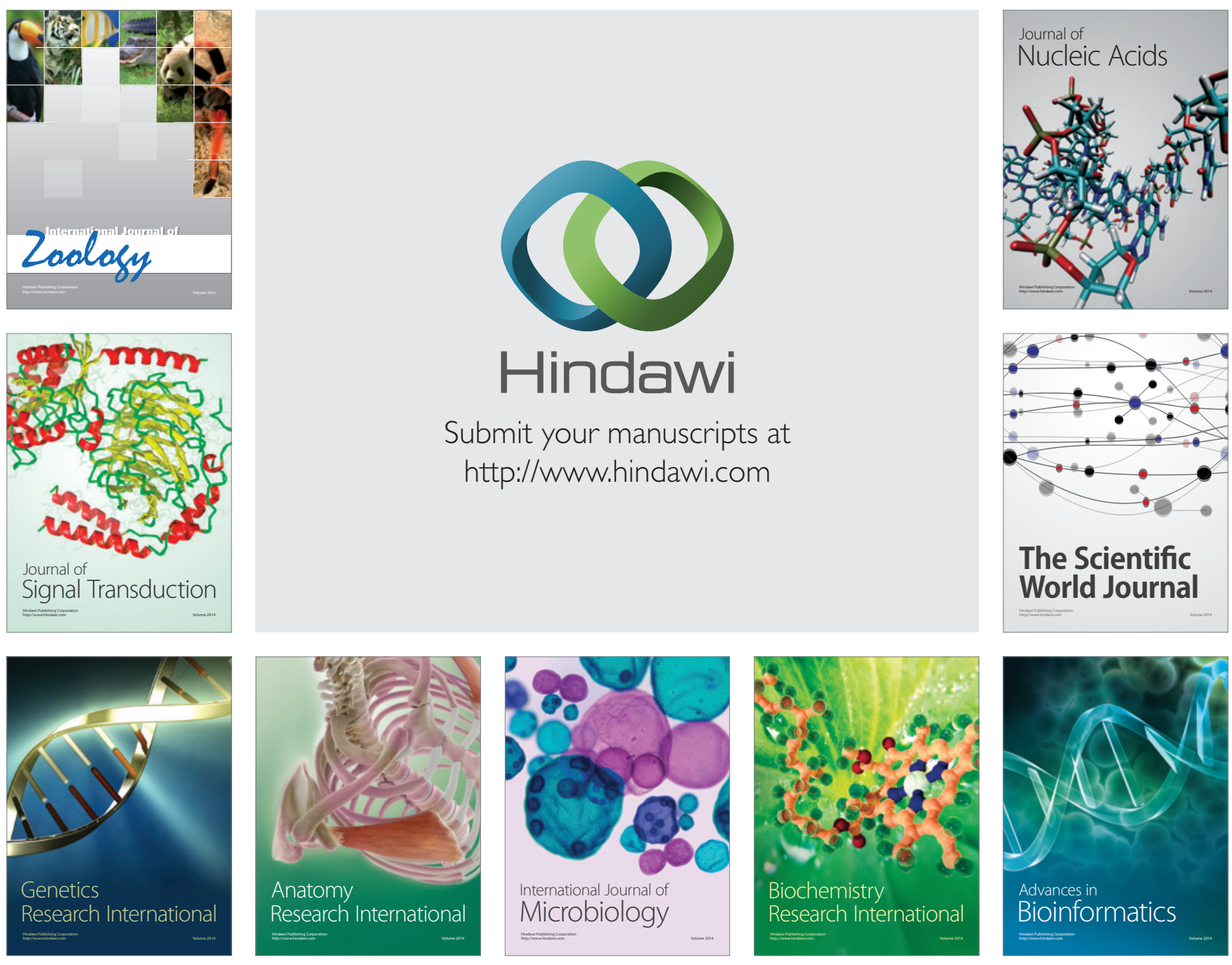

The Scientific World Journal
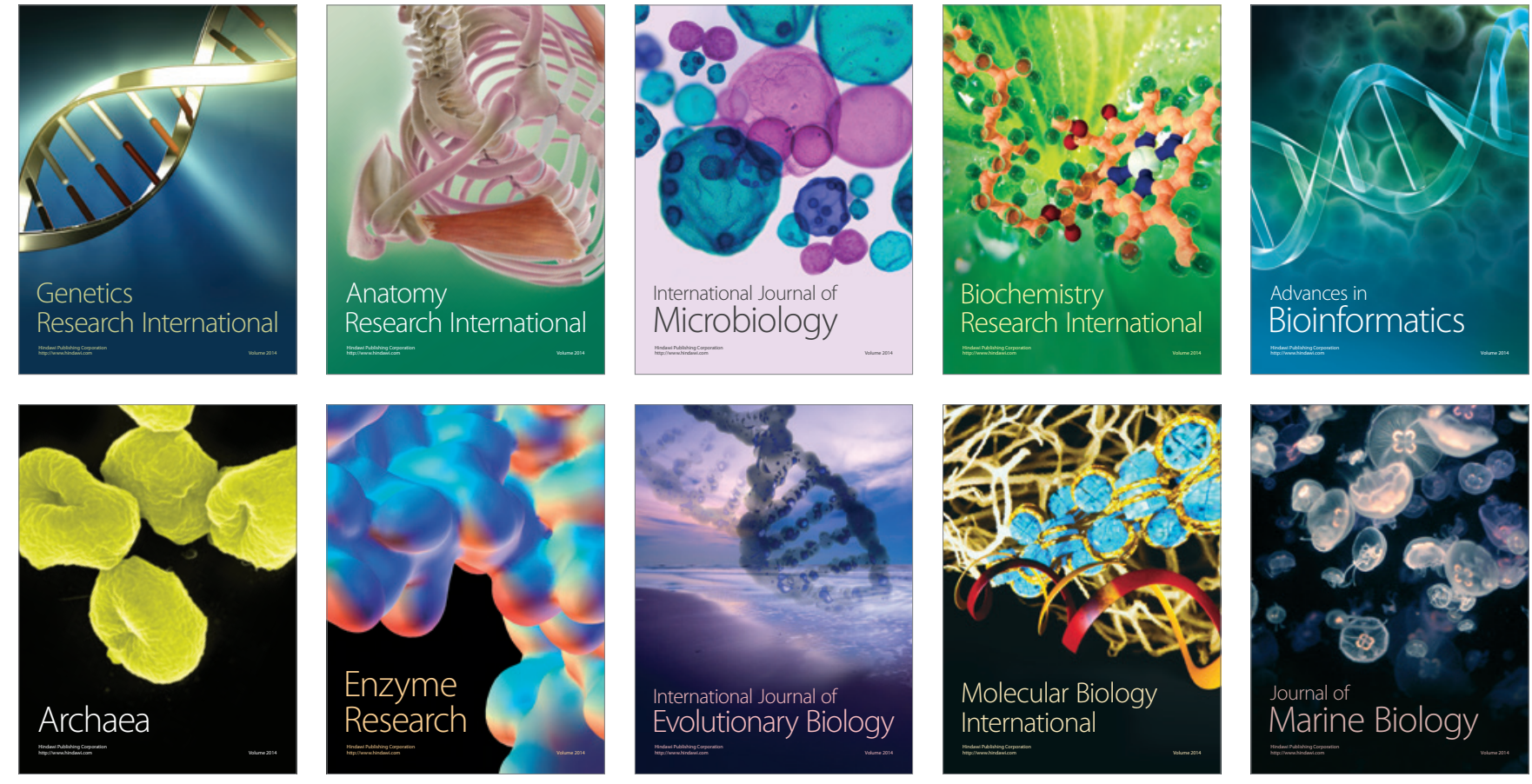